\title{
PR-СОПРОВОЖДЕНИЕ ВЫСТАВОК НА ПРИМЕРЕ ГАЛЕРЕИ СОВРЕМЕННОГО ИСКУССТВА ГАРАЖ
}

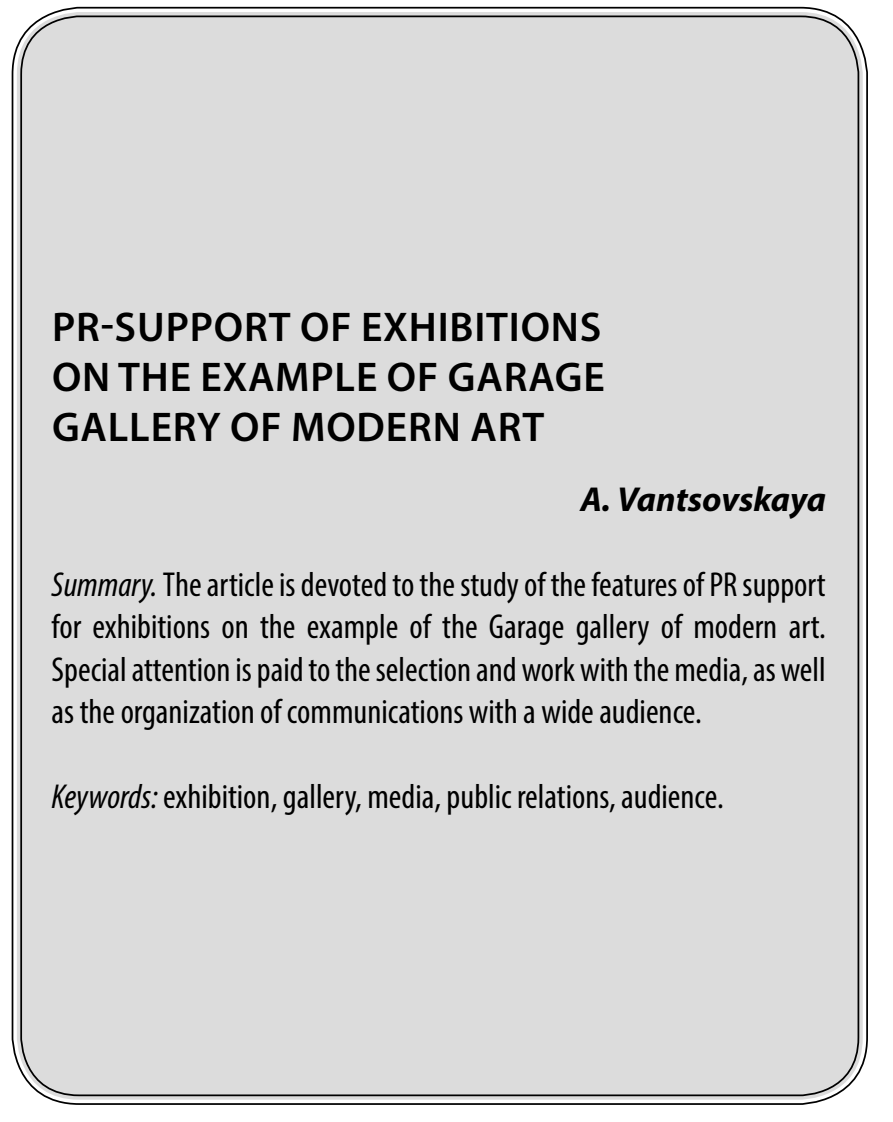

$\mathbf{X}$ удожественная галерея - относительно новая форма институциализации культурного процесса, которая отличается от классического музея своей специфической ориентацией на феномен массовой культуры. Большинство галерей, сегодня специализируется на современном творческом процессе, ярким примером такого культурного объекта является галерея современного искусства Гараж, которая была основана в 2008 году и находится на пятом месте по посещаемости среди музеев города Москвы [1].

Именно в сегменте современного творческого процесса галерея Гараж имеет широкие возможности для поиска авторов, построения их имиджа, пропаганды творчества, рекламы и продвижения произведений. Чтобы достигать обозначенных целей галерея по своему содержанию и функциональному назначению должна быть центром художественной жизни, органично включенным в современный социум, мировые информационные сети. При этом, жесткая конкуренция на рынке вынуждает учреждения культуры искать и апробировать
Ванцовская Анна Александровна

Российский университет дружбы народов vantsovskaya96@mail.ru

Аннотация. Статья посвящена исследованию особенностей PR-сопровождения выставок на примере галереи современного искусства Гараж. 0тдельное внимание уделено выбору и работе со СМИ, а также организации коммуникаций с широкой аудиторией.

Ключевые слова: выставка, галерея, СМИ, связи с общественностью, аудитория.

новые формы и методы коммуникаций. В настоящее время использование галереями традиционной рекламы уже недостаточно, в связи возникает необходимость разработки программ интегрированных маркетинговых коммуникаций, обязательным элементом которых является проведение PR-мероприятий.

PR в искусстве, так же, как и в других сферах - это система построения каналов информации. Рассматривая более предметно область функционирования галереи Гараж, отметим, что в данном случае PR - это совокупность мероприятий, которые позволят познакомить с современным искусством более широкую аудиторию и установить с нею диалог; другими словами - приобщить к современному искусству даже тех, кто при других условиях не пошел бы с ним на контакт.

В тоже время, несмотря на достаточное количество научных трудов, посвященных описанию сущности и инструментов организации связей с общественность в различных сферах общественной жизни, необходимо обра- 
тить внимание на дискуссионность подходов к трактовке сущности данной дефиниции именно в культурной сфере. Также отдельного внимания заслуживает отсутствие единой методологии PR-деятельности и особенностей ее проведения в сфере выставочного бизнеса, что требует углубления теории по вопросам формирования и функционирования организационно-экономического механизма налаживания коммуникаций между учреждениями культуры, в частности, галереями и их целевой аудиторией.

Таким образом, практический интерес к решению проблем PR-поддержки культурных мероприятий, а также объективная необходимость ее адаптации к субъектам выставочного бизнеса обусловили актуальность выбранной темы исследования и предопределили ее теоретическую и практическую значимость.

Механизмы использовании возможностей PR в деятельности предприятий с целью презентации и продвижения своей продукции отражены в ряде работ отечественных и зарубежных ученых теоретиков и практиков, из числа которых можно отметить, А. Дуровича, Ф. Котлера, С. Мельниченко, Е. Ромата и других. Особенности и алгоритм применения инструментов, которые позволяют влиять на общественное мнение в процессе проведения культурных мероприятий рассматриваются в работах таких ученых, как С. Билоусова, Л. Волокитина, В. Дмитриев, С. Семенюк. Специфика проведения маркетинговых коммуникаций в выставочной деятельности, которые дают возможность сформировать, усилить или изменить отношение общества к объектам искусства, услугам или продуктам рассматривается в работах В. Божковой, А. Костюченко, О. Евсейцевой, М. Ормонова и др.

Однако существующие на сегодняшний день результаты и наработки не являются исчерпывающими и оставляют еще много спорных и не до конца проработанных вопросов в области развития современных маркетинговых коммуникаций учреждениями культуры, в том числе и галереями.

Таким образом, с учетом вышеизложенного цель статьи заключается в исследовании PR-сопровождения выставок на примере галереи современного искусства Гараж.

Итак, цель PR при проведении выставки современного искусства в галерее Гараж заключается в достижении взаимопонимания и установлении плодотворных отношений между художниками, их работами и аудиторией путем двусторонней коммуникации. Здесь важно учесть, что без информационного продвижения на современном этапе новая выставка, событие рискует потеряться, нивелировав приложенные усилия, лишив, галерею и художников возможных продаж. Ценность PR - в его масштабном подходе, именно от него будет зависеть успех бренда в коммерческой и публичной деятельности.

Поэтому на первом этапе организации коммуникаций с общественностью, прежде всего, необходимо выбрать каналы взаимодействия, с помощью СМИ или социальных сетей, это зависит от целевой аудитории выставки или проекта, его привлекательности, характера работ и степени популярности художника.

При этом следует отметить, что медиапартнеров может быть много, однако ценность сотрудничества с ними зависит отнюдь не от количества, а от качества разработанного информационного материала, контента. И на этом, на креативной составляющей, необходимо настаивать. По мнению автора галерее Гараж лучше взять несколько партнеров из совершенно разных сфер, например - арт-СМИ (например, Moscow Art Magazine, «Русское искусство», «Наше наследие», «Мир Музея»), общественно-политические (Politrussia.com, «Эхо России»), бизнес-сайты (Анатомия бизнеса, 1000 идей и т.д.). Такой подход обоснован тем, что искусством интересуются не только люди, которые целенаправленно читают прессу о культуре, но и те, кого интересует, например, инвестиционный бизнес. Соответственно и подача информации для разных изданий должна быть разной. Если СМИ будут выбраны правильно, тогда целевая аудитория галереи будет получать нужную информацию, способную привлечь ее внимание и сформировать нужную мысль о проекте.

Для составления правильного контента следует проработать несколько сюжетных линий, расставить акценты, а также наполнить материалы фактами, цифрами и цитатами.

Особе внимание в процессе проведения выставки и привлечения посетителей необходимо уделить широкой аудитории. Типичными ошибками галереи являются следующие - рядом с большим количеством картин нет табличек с аннотациями, зато в залах размещены распечатки, зачастую в одном экземпляре, с именами авторов, описаниями работ и ценами на те из них, которые продаются. Такая ситуация вносит определенную сумятицу - по крайней мере, для той части аудитории, которая, собственно, и является ключевой для организаторов. Очевидно, что представители профессиональной среды разберутся и без объяснений. Но для широкой общественности таблички, а также аудиогиды необходимы.

Как свидетельствует мировой опыт, «представителя широкой аудитории надо брать за руку и водить по галерее понятными траекториям» [2]. Отсутствие продуман- 
ной системы выставочного пространства, сознательный отказ от подсказок и акцентов может привести к потерям галереи, как репутационным, так и финансовым.

В отдельную категорию необходимо выделить пресс-релизы. Галерее не следует скупиться на хороших копирайтеров. Хорошая речь, эпитеты, отборный фактаж и тренды - все это должно отражать элитарность культуры, которую она продает. То есть, если размещается материал в политических, бизнес ориентированных
СМИ, им будет интересна стоимость работ, возможность инвестирования в них. Если же речь идет о глянце или культурных сайтах в данном случае, необходим эксклюзивный контент, возможно, на более узкую тему.

Значительного эффекта можно достичь при проведении презентации работ художников, гала-вечеров с коллекционерами и инвесторами, дилерских конференций, с обязательным привлечением и участием в мероприятиях представителей СМИ.

1. Музей современного искусства Гараж URL: https://garagemca.org/ru

2. Vero, C. Marketing and public relations for museums, galleries, cultural and heritage attractions // Journal of heritage tourism. 2012. № 4. Pp. 371-372.

( ) Ванцовская Анна Александровна ( vantsovskaya96@mail.ru ).

Журнал «Современная наука: актуальные проблемы теории и практики»

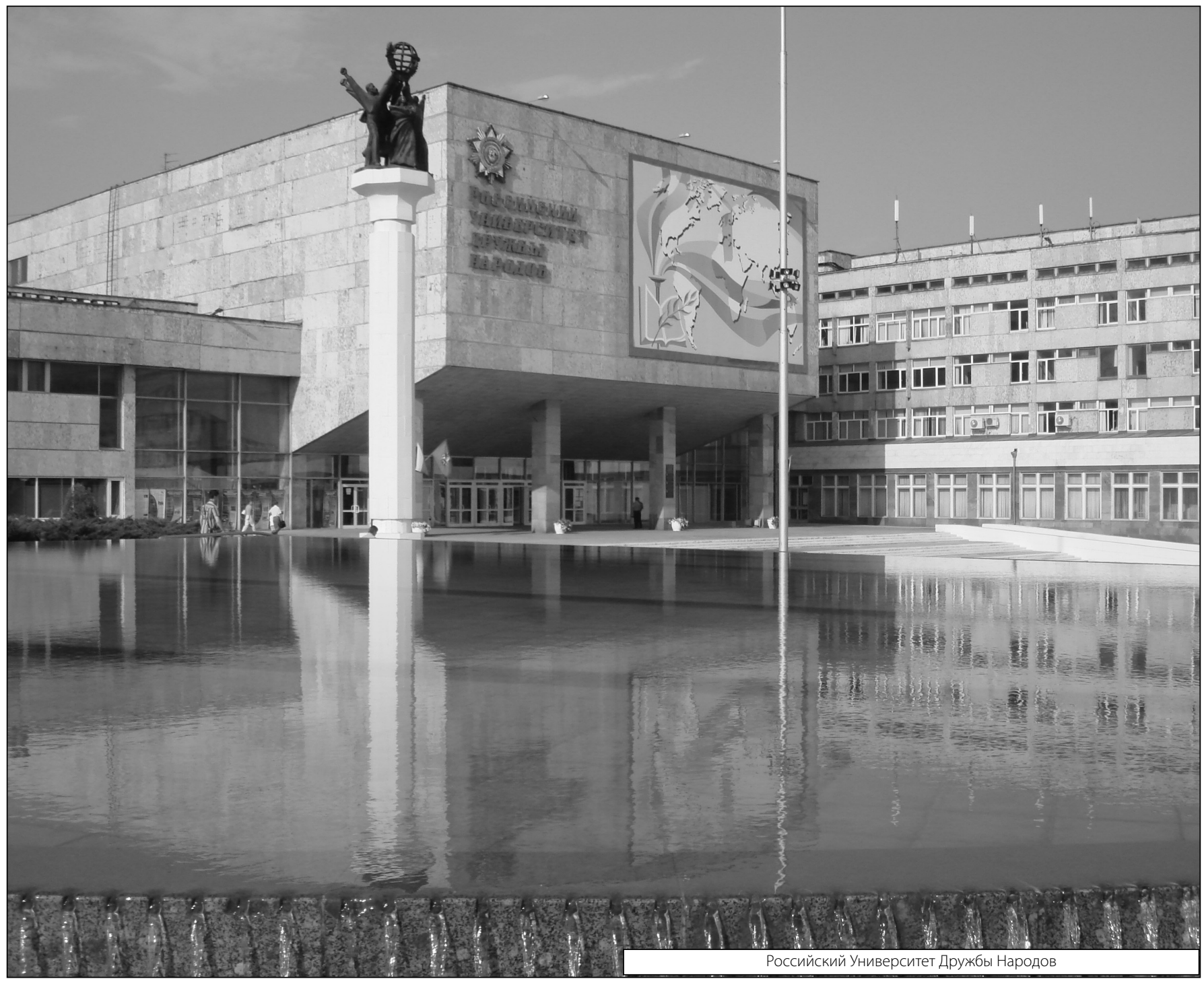

